\title{
Hypolipidemic effects of kaempferide-7-O-(4''-O-acetylrhamnosyl) -3-O-rutinoside in hyperlipidemic rats induced by a high-fat diet
}

\author{
XUE-ZHONG ZHAO ${ }^{1,3}$, XU-WEN LI ${ }^{2}$, YONG-RI JIN ${ }^{2}$, XIAO-FENG YU ${ }^{1}$, SHAO-CHUN QU ${ }^{1}$ and DA-YUAN SUI ${ }^{1}$ \\ Departments of ${ }^{1}$ Pharmacology, and ${ }^{2}$ Analytical Chemistry, College of Pharmacy, and \\ ${ }^{3}$ Department of Cardiovascular Medicine, First Hospital, Jilin University, Changchun 130021, P.R. China
}

Received August 19, 2011; Accepted December 12, 2011

DOI: $10.3892 / \mathrm{mmr} .2011 .714$

\begin{abstract}
Kaempferide-7-O-(4"-O-acetylrhamnosyl)-3-Orutinoside (A-F-B) is a novel flavonoid which is extracted from the leaves of Actinidia kolomikta. The aim of this study was to investigate the hypolipidemic effects of A-F-B in hyperlipidemic rats induced by a high-fat diet. Male Wistar rats were randomly divided into six groups: normal diet group, high-fat diet group, lovastatin $(2.5 \mathrm{mg} / \mathrm{kg})$ group and A-F-B $(12.5,25$ or $50 \mathrm{mg} / \mathrm{kg})$ groups. To evaluate the lipid-lowering effects of A-F-B, total cholesterol (TC), triglyceride (TG), low-density lipoprotein cholesterol (LDL-C), high-density lipoprotein cholesterol (HDL-C), atherogenic index (AI) and coronary risk index (CRI) were investigated. The activities of phosphatidate phosphohydrolase (PAP) and hydroxymethylglutaryl coenzyme A (HMG-CoA) reductase in hepatic tissue were evaluated. Treatment with A-F-B to hyperlipidemic rats resulted in a significant decline in TC, TG, LDL-C, AI and CRI, with an increase in HDL-C level. The results also showed that A-F-B significantly decreased the activities of PAP and HMG-CoA reductase in hepatic tissue. These findings suggest that A-F-B improves lipid profiles. The mechanisms of A-F-B were associated with regulating the activities of PAP and HMG-CoA reductase in hepatic tissue.
\end{abstract}

\section{Introduction}

Dyslipidemia refers to increased levels of total cholesterol (TC), triglyceride (TG), low-density lipoprotein cholesterol (LDL-C) and decreased level of high-density lipoprotein cholesterol (HDL-C) in the blood (1). Dyslipidemia is an independent major risk factor that, alone or together, accelerates the development of coronary artery disease and the progression of atherosclerotic lesions (2). The evidence of a previous study showed that treatment of older high-risk subjects with lipid-lowering drugs reduces cardiovascular morbidity and mortality (3).

Correspondence to: Dr Da-Yuan Sui, Department of Pharmacology, College of Pharmacy, Jilin University, Changchun 130021, P.R. China E-mail: dayuansui@yahoo.cn

Key words: kaempferide-7-O-(4"-O-acetylrhamnosyl)-3-O-rutinoside, hypolipidemic, high-fat diet
The kiwifruit (Actinidia deliciosa), originally known as the Chinese gooseberry, is native to northern China, Korea, Siberia and Japan. It is commercially available in New Zealand as well as several other fruit-producing countries. The fruit and flowers of kiwifruit contain a number of nutritional compounds, including vitamin $\mathrm{C}$, vitamin $\mathrm{E}$, folate, potassium and magnesium (4). Kiwifruit also contains plant secondary metabolites, such as ursolic acid, carotenoids and a range of polyphenols (5). It is reported that kiwifruit has anti-oxidant activity in vitro (6). Kiwifruit also protects against oxidative DNA damage or oxidative stress in vivo (7). Actinidia kolomikta belongs to the family of kiwifruit. Recently, seven new compounds have been isolated and identified from the leaves of Actinidia kolomikta. Kaempferide-7-O-(4"-Oacetylrhamnosyl)-3-O-rutinoside (A-F-B), a type of flavonoid, is one of the seven new compounds.

Extracts of plants are generally considered to be less toxic and less prone to side effects than drugs manufactured by chemical synthesis. Therefore, the study of new natural agents which are capable of regulating serum lipid levels has become an important research focus. Increasing evidence has demonstrated that the flavonoids from various plants improve dyslipidemia (8-10). Here, we hypothesized that A-F-B exerts hypolipidemic effects in rats. In the present study, the effects of A-F-B on TC, TG, LDL-C and HDL-C in rats fed a high-fat diet were investigated. The activities of hepatic phosphatidate phosphohydrolase (PAP) and hydroxymethylglutaryl coenzyme A (HMG-CoA) reductase were also measured.

\section{Materials and methods}

Chemicals. Lovastatin, hydroxylamine hydrochloride, Tris-HCl buffer, phosphatidate, trichloroacetic acid and dithiothreitol (DTT) were purchased from Sigma (St. Louis, MO, USA). Ethylene diaminetetra acetic acid (EDTA) and ethylene glycol tetraacetic acid (EGTA) were from Merck (Darmstadt, Germany). All other chemicals were of the highest quality available. TC, TG, LDL-C and HDL-C kits were purchased from the Institute of Jiancheng Biotechnology, Nanjing, China.

Preparation of A-F-B. The leaves of Actinidia kolomikta were collected in Jingyu Country, on the Changbai Mountain of China, in June 2008 and authenticated by Professor Minglu Deng of Changchun University. The dried, 
powdered leaves $(2 \mathrm{~kg}$ ) were mixed and added to 6-fold of $90 \%$ ethanol. They were refluxed four times for $2 \mathrm{~h}$ each time at room temperature. After filtration, the ethanol extracts were added to a non-polar macroporous resin (AB-8 Anhui, China) column and washed with water and $90 \%$ ethanol. Then, the eluent was treated using a decompressed drying method to obtain the extract of Actinidia kolomikta. The extract was again dissolved with $75 \%$ ethanol and acetone was added. The suspension was filtrated, and the precipitate was subjected to silica gel column chromatography $(2 \times 20 \mathrm{~cm})$ and eluted with a stepwise gradient of ethyl acetate:ethanol: $\mathrm{H}_{2} \mathrm{O}$ (10:1:0.3). It underwent further chromatography on silica gel columns, employing the same eluent systems, to provide A-F-B. The yield of the extract as a dried material was $1.4 \% \mathrm{wt}$ of the original material. Further analysis by RP-HPLC showed that the content of A-F-B in the resultant extract was $99.4 \%$.

Animals. Male Wistar rats weighing 180-220 g were obtained from the Experimental Animal Center of Jilin University. They were housed individually in a well-ventilated animal unit $\left(22 \pm 2^{\circ} \mathrm{C}\right.$, humidity $60 \pm 5 \%, 12$-h light/dark cycle) and had free access to rodent chow and water ad libitum. All animal experiments were conducted according to the Guide for the Care and Use of Laboratory Animals published by the National Institutes of Health (NIH publication no. 85-23, revised 1996) and Committee of Jilin University for the Care and Use of Laboratory Animals.

Experimental design. Sixty rats were fed a basic diet for 1 week before the experiments were conducted and then they were divided into 6 groups of 10 animals each: control group $(\mathrm{CON})$, high-fat diet group (HFD), lovastatin $(2.5 \mathrm{mg} / \mathrm{kg})$ group and A-F-B $(12.5,25$ or $50 \mathrm{mg} / \mathrm{kg})$ groups. The animals in the $\mathrm{CON}$ received a basic diet, while the other rats were fed a high-fat diet, as presented in Table I, during 4 weeks of the experimental period. A-F-B groups were orally administered with A-F-B at the dose of $12.5,25$ or $50 \mathrm{mg} / \mathrm{kg}$. The lovastatin group received lovastatin at the dose of $2.5 \mathrm{mg} / \mathrm{kg}$, while the rats in CON and HFD were treated with the same volume of distiledl water once daily for 4 weeks. At the end of the experimental period and after $12 \mathrm{~h}$ of fasting, animals were anesthetized with chloral hydrate $(350 \mathrm{mg} / \mathrm{kg}$, intraperitoneally injected).

Measurement of TC, TG, LDL-C and HDL-C. Five milliliters blood were collected from the abdominal aorta at the end of each experiment. The samples were left at room temperature for $1 \mathrm{~h}$ to allow complete clotting and then centrifuged $(2,500 \mathrm{x} \mathrm{g})$ at $4^{\circ} \mathrm{C}$ for $15 \mathrm{~min}$ to obtain the serum. TC, TG, LDL-C and HDL-C were detected using commercial kits according to the manufacturer's instructions. All analyses employed an automated analyzer (7020 Clinical Analyzer; Hitachi, Tokyo, Japan). The atherogenic index (AI) and coronary risk index (CRI) were calculated as follows (11): AI = LDL-C (mmol/l)/ HDL-C $(\mathrm{mmol} / \mathrm{l})$, and CRI = TC $(\mathrm{mmol} / \mathrm{l}) / \mathrm{HDL}-\mathrm{C}(\mathrm{mmol} / \mathrm{l})$, respectively.

Assay of the activities of PAP and $H M G-C o A$ reductase in hepatic tissue. Freshly excised liver tissue was immediately washed with ice-cold saline $(0.9 \%)$, blotted on filter paper,
Table I. Composition (\%) of the experimental diets.

\begin{tabular}{lcc}
\hline Ingredient & Basic diet & High-fat diet \\
\hline Corn meal & 30 & 26.3 \\
Soybean meal & 20 & 17.5 \\
Wheat bran & 25 & 21.9 \\
Wheat flour & 16 & 14.0 \\
Fish meal & 5 & 4.4 \\
Bone meal & 2 & 1.8 \\
Yeast powder & 1 & 0.9 \\
NaCl & 1 & 0.9 \\
Cholesterol & 0 & 2.0 \\
Lard & 0 & 10.0 \\
Sodium cholate & 0 & 0.3 \\
\hline
\end{tabular}

weighed and then cut into small pieces and homogenized in Tris-HCl buffer $(0.025 \mathrm{M}, \mathrm{pH} 7.4)$ to give a $10 \%(\mathrm{w} / \mathrm{v})$ liver homogenate. After centrifugation at $12,000 \mathrm{x} \mathrm{g}$ for $15 \mathrm{~min}$, the supernatant was stored at $-70^{\circ} \mathrm{C}$ until analysis.

PAP activity was measured in assay buffer $(250 \mu \mathrm{l})$ containing $50 \mathrm{mM}$ Tris-HCl buffer $\mathrm{pH}$ 7.4, 1 mM DTT, $1 \mathrm{mM}$ EGTA, $2 \mathrm{mM} \mathrm{MgCl}_{2}, 1 \mathrm{mM}$ EDTA, $0.35 \mathrm{mM}$ phosphatidate and $20 \mu \mathrm{l}$ of the supernatant. The assay mixture was incubated at $37^{\circ} \mathrm{C}$ for $30 \mathrm{~min}$. The reaction was stopped by adding $0.5 \mathrm{ml}$ trichloroacetic acid (10\%). Hence, the released PI was measured (12). All assays were linear in relation to the incubation time and the protein concentrations. The PAP activity was defined as the amount of enzyme that catalyzes the release of $1 \mu \mathrm{mol}$ of $\mathrm{PI} / \mathrm{min}$ under standard assay conditions. Specific activity was considered as U/mg protein. Protein concentration was determined by a previously described method (13).

Hepatic HMG-CoA reductase activity was measured from the HMG-CoA/mevalonate ratio. HMG-CoA was determined by its reaction with hydroxylamine hydrochloride at $\mathrm{pH} 5.5$ and subsequent colorimetric measurement of the resulting hydroxamic acid by formation of complexes with ferric salts at $540 \mathrm{~nm}$. Mevalonate was estimated by reaction with the same reagent but at $\mathrm{pH}$ 2.1. The ratio between $\mathrm{HMG}-\mathrm{CoA}$ and mevalonate is inversely proportional to $\mathrm{HMG}-\mathrm{CoA}$ reductase activity (14).

Statistical analysis. Data are expressed as the means \pm SD. The statistical significance of all data was determined using one-way analysis of variance (ANOVA) followed by the Tukey's post hoc test for multiple comparisons. Values of $\mathrm{P}<0.05$ were considered to denote statistical significace.

\section{Results}

Structure of $A-F-B$. A-F-B was obtained as a yellow powder, $\mathrm{mp} 171-173^{\circ} \mathrm{C}$. The UV spectrum exhibited $\lambda_{\max }$ at 267 and $366 \mathrm{~nm}$, characteristic for a flavone skeleton. The HR-FAB-MS (Pos) gave a ion at $m / z$ 797.2487, suggesting that the molecular formula was $\mathrm{C}_{36} \mathrm{H}_{45} \mathrm{O}_{20}$ (Calcd. 797.2453). ${ }^{1} \mathrm{H}-\mathrm{NMR}(400 \mathrm{MHz}$, DMSO, J=Hz) ठ: 12.50 (1H, s, 5-OH), 8.14 (2H, d, J=8.8, 2',6'H), 7.09 (2H, d, J=8.8, 3',5'-H), 6.85 (1H, d, J=2.1, 8-H), 6.51 $(1 \mathrm{H}, \mathrm{d}, \mathrm{J}=2.1,6-\mathrm{H}), 3.86\left(3 \mathrm{H}, \mathrm{s}, 4^{\prime}-\mathrm{OCH}_{3}\right), \delta_{\mathrm{H}} 5.45(1 \mathrm{H}, \mathrm{d}, \mathrm{J}=7.6$, 
Table II. ${ }^{13} \mathrm{C}$ NMR spectral data for A-F-B in DMSO (ppm).

\begin{tabular}{|c|c|}
\hline No. & ${ }^{13} \mathrm{C}$ \\
\hline 1 & - \\
\hline 2 & 156.88 \\
\hline 3 & 133.76 \\
\hline 4 & 177.55 \\
\hline 5 & 160.81 \\
\hline 6 & 99.39 \\
\hline 7 & 161.85 \\
\hline 8 & 94.75 \\
\hline 9 & 156.03 \\
\hline 10 & 105.76 \\
\hline $1^{\prime}$ & 122.15 \\
\hline $2^{\prime}$ & 130.74 \\
\hline $3^{\prime}$ & 113.67 \\
\hline $4^{\prime}$ & 161.24 \\
\hline $5^{\prime}$ & 113.67 \\
\hline $6^{\prime}$ & 130.74 \\
\hline$-\mathrm{OCH}_{3}$ & 55.32 \\
\hline \multicolumn{2}{|l|}{ 7-O-sugar } \\
\hline $1 "$ & 97.39 \\
\hline $2 "$ & 69.64 \\
\hline 3" & 67.73 \\
\hline $4 "$ & 73.23 \\
\hline $5 "$ & 67.41 \\
\hline 6" & 17.59 \\
\hline \multicolumn{2}{|l|}{$\mathrm{O}$} \\
\hline$-\mathrm{C}-$ & 169.85 \\
\hline $\mathrm{CH}_{3-}^{-}$ & 20.81 \\
\hline \multicolumn{2}{|l|}{ 3-O-sugar } \\
\hline Glc-1/II & 101.22 \\
\hline Glc-2 $2^{\prime \prime \prime}$ & 74.06 \\
\hline Glc-3 $3^{\prime \prime \prime}$ & 75.66 \\
\hline Glc-4 $4^{\prime \prime \prime}$ & 69.62 \\
\hline Glc-5 $5^{\prime \prime \prime}$ & 76.26 \\
\hline Glc-6 $6^{\prime \prime \prime}$ & 66.53 \\
\hline Rha-1/III & 100.62 \\
\hline Rha-2//II & 70.54 \\
\hline Rha-3 ${ }^{\prime \prime \prime \prime}$ & 70.26 \\
\hline Rha-4"/II & 71.71 \\
\hline Rha-5 $5^{\prime / \prime \prime}$ & 68.14 \\
\hline Rha-6 'III $^{\prime \prime}$ & 17.38 \\
\hline
\end{tabular}

glc1-H), $\delta_{\mathrm{H}} 4.42(1 \mathrm{H}, \mathrm{d}, \mathrm{J}=4.2$, rha1-H), 3.32 (1H, m, rha2-H), $3.36(1 \mathrm{H}, \mathrm{m}$, rha3 $-\mathrm{H}), 4.02(1 \mathrm{H}, \mathrm{m}$, rha4-H), 3.35 (1H, m, rha5H), 0.97 (1H, d, J=6.4, rha6-H), $\delta_{\mathrm{H}} 5.64$ (1H, s, 7-O-rha1-H), 3.93 (1H, br-s, 7-O-rha2-H), 3.88 (1H, m, 7-O-rha3-H), 4.89 (1H, t, J=9.6, 7-O-rha4-H), 3.64 (1H, m, 7-O-rha5-H), 1.03 $(3 \mathrm{H}, \mathrm{d}, \mathrm{J}=6.0,7-\mathrm{O}-\mathrm{rha} 6-\mathrm{H}), 2.05\left(3 \mathrm{H}, \mathrm{s},-\mathrm{COCH}_{3}\right)$ (Table II). The structure of A-F-B was identified as Kaempferide-7-O(4"-O-acetylrhamnosyl)-3-O-rutinoside (Fig. 1).

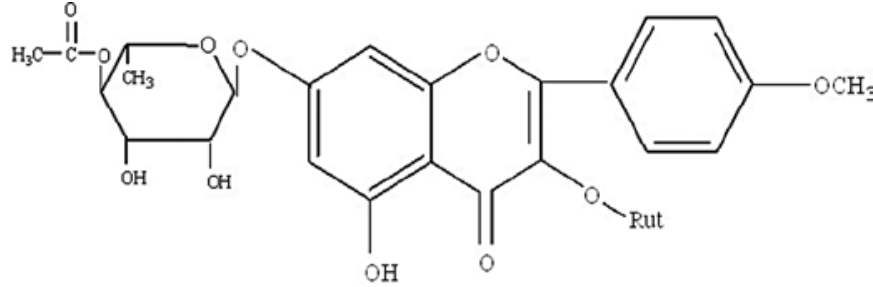

Figure 1. Structure of kaempferide-7-O-(4"-O-acetylrhamnosyl)-3-O-rutinoside.

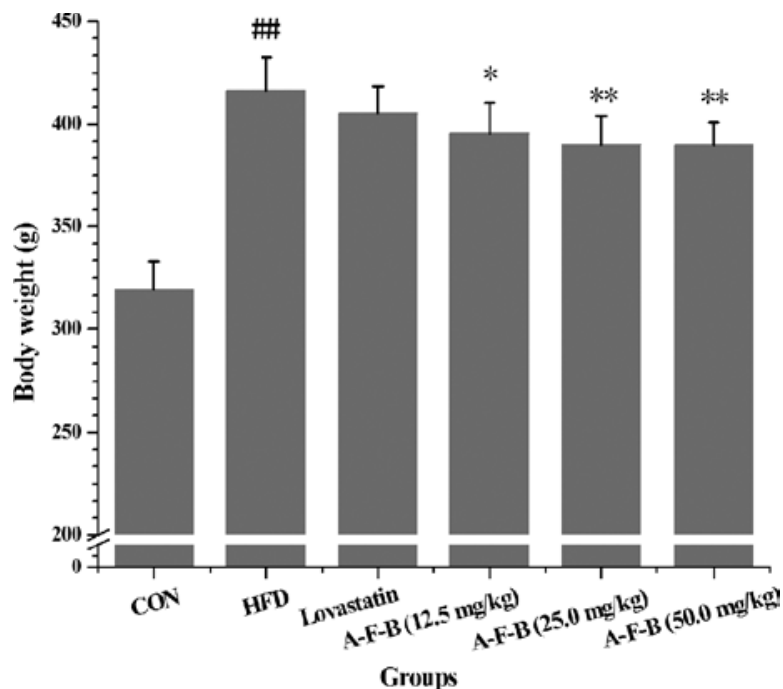

Figure 2. Effects of A-F-B on body weight in hyperlipidemic rats. The body weight of the rats treated with A-F-B at doses of $12.5,25$ or $50 \mathrm{mg} / \mathrm{kg}$ was reduced as compared to the HFD rats. Data were expressed as the means \pm $\mathrm{SD}(\mathrm{n}=10) .{ }^{\# \prime} \mathrm{P}<0.01$ compared to the control group; ${ }^{*} \mathrm{P}<0.05,{ }^{* *} \mathrm{P}<0.01$ compared to the HFD group.

Effects of $A-F-B$ on body weight in hyperlipidemic rats. Compared to the CON rats, the body weight of HFD rats was significantly increased. However, the body weight of the rats treated with A-F-B at doses of $12.5,25$ or $50 \mathrm{mg} / \mathrm{kg}$ was reduced as compared to the HFD rats $(\mathrm{P}<0.05$ or $\mathrm{P}<0.01$ Fig. 2). Compared to the HFD group, no significant change was observed in body weight in the lovastatin group.

Effect of A-F-B on TG, TC, LDL-C,HDL-C, AI and CRI in hyperlipidemic rats. Table III shows the plasma levels of TG, TC, LDL-C, HDL-C, AI and CRI in the CON, HFD and animals treated with A-F-B in each group. Compared to the CON, the levels of TG, TC, LDL-C, AI and CRI in the HFD group were significantly increased, while the levels of HDL-C were decreased $(\mathrm{P}<0.01)$. However, treatment with A-F-B or lovastatin inhibited not only the increase in TG, TC, LDL-C, AI and CRI, but also the decrease in HDL-C $(\mathrm{P}<0.05$ or $\mathrm{P}<0.01)$.

Effect of A-F-B on hepatic PAP activity in hyperlipidemic rats. The PAP activity in the hepatic tissue of the HDF group was significantly increased in comparison to the CON group $(\mathrm{P}<0.01)$. Treatment with A-F-B $(12.5,25$ or $50 \mathrm{mg} / \mathrm{kg})$ or lovastatin for 4 weeks led to a significant decrease in the PAP activity in the hepatic tissue as compared to that in the HDF group $(\mathrm{P}<0.05$ or $\mathrm{P}<0.01$, Fig. 3$)$. 
Table III. Effect of A-F-B on TC, TG, LDL-C and HDL-C levels, and AI and CRI in hyperlipidemic rats.

\begin{tabular}{lcccccc}
\hline Group & $\begin{array}{c}\text { TG } \\
(\mathrm{mmol} / \mathrm{l})\end{array}$ & $\begin{array}{c}\text { TC } \\
(\mathrm{mmol} / \mathrm{l})\end{array}$ & $\begin{array}{c}\text { LDL-C } \\
(\mathrm{mmol} / \mathrm{l})\end{array}$ & $\begin{array}{c}\text { HDL-C } \\
(\mathrm{mmol} / \mathrm{l})\end{array}$ & AI & CRI \\
\hline CON & $0.98 \pm 0.18$ & $1.11 \pm 0.25$ & $1.63 \pm 0.19$ & $1.66 \pm 0.13$ & $1.02 \pm 0.23$ & $0.72 \pm 0.19$ \\
HFD & $1.61 \pm 0.31^{\mathrm{a}}$ & $4.36 \pm 0.65^{\mathrm{a}}$ & $2.18 \pm 0.22^{\mathrm{a}}$ & $0.99 \pm 0.23^{\mathrm{a}}$ & $2.23 \pm 0.28^{\mathrm{a}}$ & $4.49 \pm 0.90^{\mathrm{a}}$ \\
Lovastatin & $1.19 \pm 0.19^{\mathrm{c}}$ & $3.32 \pm 0.62^{\mathrm{c}}$ & $1.70 \pm 0.16^{\mathrm{c}}$ & $1.43 \pm 0.22^{\mathrm{c}}$ & $1.20 \pm 0.20^{\mathrm{c}}$ & $2.35 \pm 0.48^{\mathrm{c}}$ \\
A-F-B $(12.5 \mathrm{mg} / \mathrm{kg})$ & $1.21 \pm 0.23^{\mathrm{c}}$ & $3.55 \pm 0.51^{\mathrm{c}}$ & $1.87 \pm 0.25^{\mathrm{b}}$ & $1.26 \pm 0.22^{\mathrm{b}}$ & $1.53 \pm 0.32^{\mathrm{c}}$ & $2.89 \pm 0.30^{\mathrm{c}}$ \\
A-F-B $(25 \mathrm{mg} / \mathrm{kg})$ & $1.24 \pm 0.16^{\mathrm{c}}$ & $3.54 \pm 0.70^{\mathrm{c}}$ & $1.80 \pm 0.30^{\mathrm{c}}$ & $1.30 \pm 0.19^{\mathrm{b}}$ & $1.43 \pm 0.34^{\mathrm{c}}$ & $2.79 \pm 0.90^{\mathrm{c}}$ \\
A-F-B $(50 \mathrm{mg} / \mathrm{kg})$ & $1.06 \pm 0.17^{\mathrm{c}}$ & $3.44 \pm 0.73^{\mathrm{c}}$ & $1.74 \pm 0.19^{\mathrm{c}}$ & $1.34 \pm 0.19^{\mathrm{c}}$ & $1.32 \pm 0.19^{\mathrm{c}}$ & $2.60 \pm 0.54^{\mathrm{c}}$ \\
\hline
\end{tabular}

Levels of TG, TC, LDL-C, AI and CRI in the HFD group were significantly increased, while the levels of HDL-C were decreased when compared to the CON. However, treatment with A-F-B $(12.5,25$ or $50 \mathrm{mg} / \mathrm{kg})$ for 4 weeks inhibited not only the increase in TG, TC, LDL-C, AI and CRI, but also the decrease in HDL-C. Data are expressed as the means $\pm \mathrm{SD}(\mathrm{n}=10)$. ${ }^{\mathrm{a}} \mathrm{P}<0.01$ compared to the control group; ${ }^{\mathrm{b}} \mathrm{P}<0.05 \mathrm{compared}$ to the HFD group; ${ }^{~} \mathrm{P}<0.01$ compared to the HFD group. TC, total cholesterol; TG, triglyceride; LDL-C, low-density lipoprotein cholesterol; HDL-C, high-density lipoprotein cholesterol; AI, atherogenic index; CRI, coronary risk index; CON, control group; HFD, high-fat diet group.

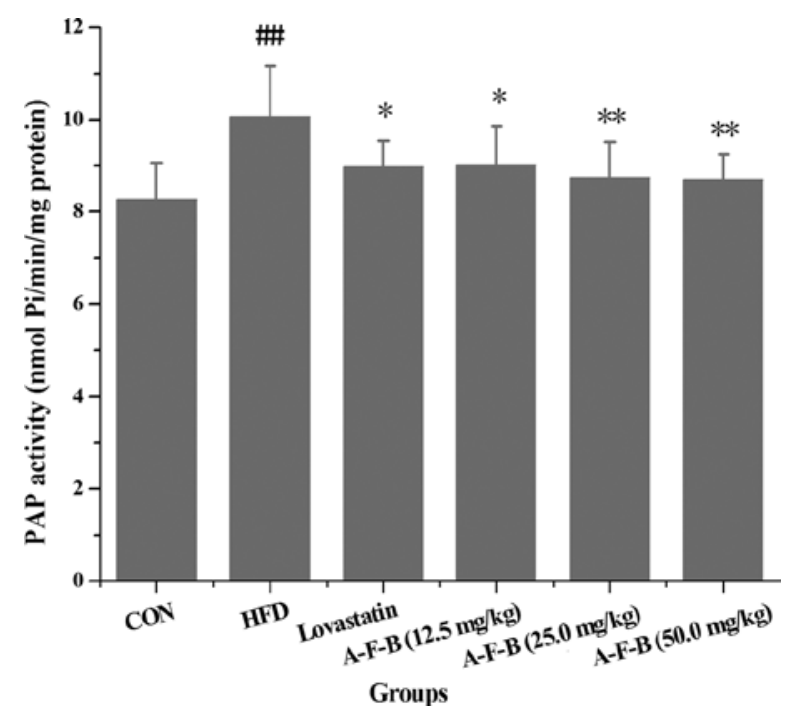

Figure 3. Effects of A-F-B on PAP activity in hyperlipidemic rats. Treatment with A-F-B $(12.5,25$ or $50 \mathrm{mg} / \mathrm{kg})$ or lovastatin for 4 weeks reduced the PAP activity in hepatic tissue as compared to that in the HDF group. Data are expressed as the means $\pm \mathrm{SD}(\mathrm{n}=10)$. ${ }^{\# \#} \mathrm{P}<0.01$ compared to the control group; ${ }^{*} \mathrm{P}<0.05,{ }^{* *} \mathrm{P}<0.01$ compared to the HFD group.

Effect of A-F-B on hepatic $H M G-C o A$ reductase activity in hyperlipidemic rats. Measurements of hepatic HMG-CoA reductase activity revealed a significant increase in the HDF group $(\mathrm{P}<0.01)$. Compared to the HDF group, the HMG-CoA reductase activity in the $\mathrm{A}-\mathrm{F}-\mathrm{B}$ groups and lovastatin group was markedly decreased ( $\mathrm{P}<0.05$ or $\mathrm{P}<0.01$; Fig. 4).

\section{Discussion}

Hypercholesterolemia and hypertriglyceridemia are major risk factors for the development of cardiovascular disease. Reducing the level of TC and TG in the serum is an effective method to treat atherosclerosis. In the present study, the rats fed a high-fat diet had a higher concentration of serum TC and TG as compared to the rats maintained on a basic diet. However, there was an obvious reduction in serum TC and TG levels in the hyperlipidemic rats treated with A-F-B. It

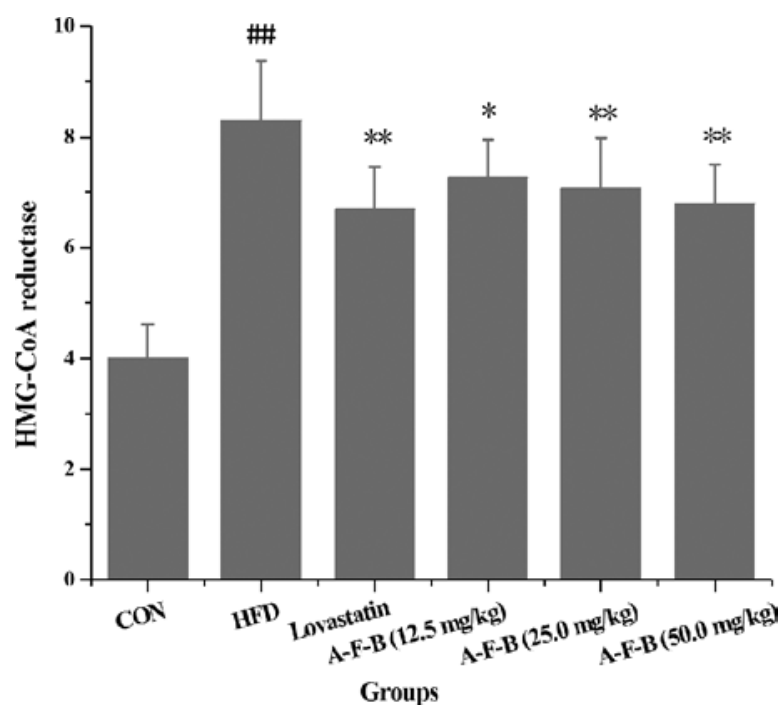

Figure 4. Effects of A-F-B on HMG-CoA reductase activity in hyperlipidemic rats. Compared to the HDF group, the HMG-CoA reductase activity in the A-F-B groups and lovastatin group was markedly decreased. Data are expressed as the means $\pm \mathrm{SD}(\mathrm{n}=10) .{ }^{\# \#} \mathrm{P}<0.01$ compared to the control group; ${ }^{*} \mathrm{P}<0.05,{ }^{* *} \mathrm{P}<0.01$ compared to the HFD group.

has also been reported that an elevated level of LDL-C is a major risk factor for cardiovascular disease (15). The level of HDL-C is thought to reflect the rate of removal of excess peripheral cholesterol, and an elevated level of HDL-C is thereby associated with a reduced risk of atherosclerosis. The current results showed that the level of LDL-C was reduced and the level of HDL-C was increased in the animals receiving a high-fat diet and additionally administered A-F-B as compared to the rats fed a high-fat diet alone. The $\mathrm{AI}$ and CRI, determined as the ratio of TC to HDL-C, or LDL-C to HDL-C, are the diagnostic indicators of the risk of atherosclerosis development. The data of the present experiment indicated that treatment with A-F-B also caused a significant reduction in AI and CRI in the hyperlipidemic rats. These findings demonstrated that A-F-B has therapeutic potential in the management of hyperlipidaemia and in the prevention of cardiovascular disease. 
PAP catalyzes the dephosphorylation of phosphatidic acid to yield inorganic phosphate and diacylglycerol. The produced diacylglycerol serves as a precursor for the synthesis of major glycerolipids in cells. The reaction catalyzed by PAP is a regulatory step in the synthesis of TG and phospholipids. TG is the major energy storage molecule that allows organisms to survive periods of food deprivation. However, the regulation of TG storage is very important in cardiovascular diseases as excessive fat storage is accompanied by dyslipidemia (16). To elucidate the mechanism of the triacylglycerol-lowering action of A-F-B, liver PAP enzyme activity involved in TG biosynthesis was measured. Our data showed that A-F-B treatment reduced the PAP activity in hyperlipidemic rats. Therefore, it is reasonable to conclude that the serum TG reduction in A-F-B groups was due to the decline in PAP activity in the liver.

One of the ways for the body to acquire cholesterol is from food. The other is biological synthesis in the body, which accounts for $70-80 \%$ of total cholesterol in the serum. Thus, inhibition of the biological synthesis of cholesterol is an effective method to lower the level of cholesterol. HMG-CoA reductase catalyzing an NADPH-dependent reduction in HMG-CoA to mevalonate is the first committed step in cholesterol biosynthesis (17). The present results showed that treatment with A-F-B caused profound reduction in hepatic HMG-CoA reductase activity, which strongly suggests that the inhibition of HMG-CoA reductase activity was partially associated with the hypolipidemic effects of A-F-B.

Compared to control rats, the body weights of rats fed a high-fat diet were increased, and this weight increase was ascribed to increased calorie intake and the accumulation of body fat. Notably, in the present study, the animals treated with A-F-B showed a significant reduction in total weight gain. We hypothesize that the weight reduction may be related to the hypolipidemic effects of A-F-B. However, further experiments should be carried out in order to elucidate the mechanisms of the anti-obesity effect of A-F-B.

In conclusion, the present study demonstrated that A-F-B reduces TC, TG, LDL-C, AI and CRI, and increases the level of HDL-C in hyperlipidemic rats. A-F-B also decreases the activities of PAP and HMG-CoA reductase in hepatic tissue. These findings suggest that A-F-B administration improves lipid profiles. The mechanisms of A-F-B are associated with the regulation of the activities of PAP and $\mathrm{HMG}-\mathrm{CoA}$ reductase in hepatic tissue.

\section{References}

1. Chen Z, Peto R, Collins R, MacMahon S, Lu J and Li W: Serum cholesterol concentration and coronary heart disease in a population with low cholesterol concentrations. BMJ 303: 276-282, 1991.

2. McKenney JM: Pharmacotherapy of dyslipidemia. Cardiovasc Drugs Ther 15: 413-422, 2001

3. Aronow WS: Treatment of high-risk older persons with lipidlowering drug therapy. Am J Ther 15: 102-107, 2008.

4. Rush EC, Patel M, Plank LD and Ferguson LR: Kiwifruit promotes laxation in the elderly. Asia Pac J Clin Nutr 11: 164-168, 2002.

5. Dawes HM and Keene JB: Phenolic composition of kiwifruit juice. J Agric Food Chem 47: 2398-2403, 1999.

6. Fiorentino A, D'Abrosca B, Pacifico S, Mastellone C, Scognamiglio M and Monaco P: Identification and assessment of antioxidant capacity of phytochemicals from kiwi fruits. J Agric Food Chem 57: 4148-4155, 2009.

7. Collins AR, Harrington V, Drew J and Melvin R: Nutritional modulation of DNA repair in a human intervention study. Carcinogenesis 24: 511-515, 2003.

8. Zhang L, Yang J, Chen XQ, et al: Antidiabetic and antioxidant effects of extracts from Potentilla discolor Bunge on diabetic rats induced by high fat diet and streptozotocin. J Ethnopharmacol 132: 518-524,2010.

9. Park KW, Lee JE and Park KM: Diets containing Sophora japonica L. prevent weight gain in high-fat diet-induced obese mice. Nutr Res 29: 819-824, 2009.

10. Mulvihill EE, Assini JM, Sutherland BG, et al: Naringenin decreases progression of atherosclerosis by improving dyslipidemia in high-fat-fed low-density lipoprotein receptor-null mice. Arterioscler Thromb Vasc Biol 30: 742-748, 2010.

11. Adeneye AA, Adeyemi OO and Agbaje EO: Anti-obesity and antihyperlipidaemic effect of Hunteria umbellata seed extract in experimental hyperlipidaemia. J Ethnopharmacol 130: 307-314, 2010.

12. Haghighi B and Honarjou S: The effects of hydrazine on the phosphatidate phosphohydrolase activity in rat liver. Biochem Pharmacol 36: 1163-1165, 1987.

13. Lowry OH, Rosebrough NJ, Farr AL and Randall RJ: Protein measurement with the Folin phenol reagent. J Biol Chem 193: 265-275, 1951.

14. Rao AV and Ramakrishnan S: Indirect assessment of hydroxymethylglutaryl-CoA reductase (NADPH) activity in liver tissue. Clin Chem 21: 1523-1525, 1975.

15. Berliner JA and Heinecke JW: The role of oxidized lipoproteins in atherogenesis. Free Radic Biol Med 20: 707-727, 1996.

16. Hegele RA and Pollex RL: Genetic and physiological insights into the metabolic syndrome. Am J Physiol Regul Integr Comp Physiol 289: R663-R669, 2005.

17. Rozman D and Monostory K: Perspectives of the non-statin hypolipidemic agents. Pharmacol Ther 127: 19-40, 2010. 